\title{
Near-field zooplankton, ice-face biota and proximal hydrography of free-drifting Antarctic icebergs
}

\author{
R.E. Sherlock ${ }^{\mathrm{a}, *}$, K.R. Reisenbichler ${ }^{\mathrm{a}}$, S.L. Bush ${ }^{\mathrm{a}, \mathrm{b}}$, K.J. Osborn ${ }^{\mathrm{c}}$, B.H. Robison ${ }^{\mathrm{a}}$ \\ a Monterey Bay Aquarium Research Institute, 7700 Sandholdt Rd, Moss Landing, CA 95039, USA \\ b Department of Biological Sciences, College of Environment and Life Sciences, University of Rhode Island, Kingston, RI 02881, USA \\ c Scripps Institution of Oceanography, 8615 Discovery Way, La Jolla, CA 92037, USA
}

\section{A R T I C L E I N F O}

Article history:

Received 12 November 2010

Accepted 12 November 2010

\section{Keywords:}

Southern Ocean

Weddell Sea

Iceberg

Ice

Plankton

ROV

\begin{abstract}
A B S T R A C T
A small ROV was used to collect plankton, make video surveys and take hydrographic measurements in close proximity to six free-drifting, Antarctic icebergs. The icebergs studied ranged in size from $<0.5$ to $>32 \mathrm{~km}$ in length. Large icebergs have a greater scale of influence than do smaller ones and icebergmediated differences in the hydrographic characteristics of their surrounding water depend on the scale sampled. Irrespective of size, temperature generally decreased in close proximity to an iceberg while salinity increased. Chlorophyll $a$ was often lower in the surface waters near the iceberg, relative to the surface waters further away. Tabular icebergs typically had 3 distinct underwater features: shelf, side and bottom. Ablation pockets were a common feature of subsurface ice. The ice itself is a dynamic and seemingly harsh environment with relatively few macrofauna living on it. Those that do inhabit the ice face are either highly specialized or highly mobile. Species composition of zooplankton within $40 \mathrm{~m}$ of an iceberg did not change relative to distance. However, biomass was generally greater within $5 \mathrm{~m}$ of an iceberg than it was 15 to $40 \mathrm{~m}$ distant.
\end{abstract}

(c) 2010 Elsevier Ltd. All rights reserved.

\section{Introduction}

Tabular icebergs form as glaciers flow from land into the sea and calve or break off. Historically about 5000 icebergs a year calve into Antarctic waters from the Amery, Filchner and Ross ice shelves (Wadhams, 1986). Fewer in number than Arctic icebergs but larger, tabular Antarctic icebergs typically have a depth of $c a 250 \mathrm{~m}$, the mean thickness of the ice shelf at the point of calving. Large icebergs are prone to ablation by fracture and calving. Smaller icebergs can roll and the smallest icebergs are often rife with complex physical features like caves or ice spires, wrought by erosion and wastage. These dynamic aspects make getting close to icebergs both difficult and dangerous. Consequently, there have been few field observations carried out in close proximity to large, free-drifting icebergs (but see Pisarevskaya and Popov, 1990, as well as Ohshima et al., 1994 , for a study done on fast ice).

The occurrence of large icebergs ( $>18.5 \mathrm{~km}$ long) originating from ice shelves in the Ross, Bellingshausen and Weddell Seas has increased during the last decade (Scambos et al., 2000; Bindschadler and Rignot, 2001; Long et al., 2002; Bindschadler, 2006; Jacobs, 2006). Recent evidence suggests that one large iceberg (Lazzara et al., 1999) grounded in the Ross Sea drastically

\footnotetext{
* Corresponding author. Tel.: +1831 7751763 .

E-mail address: robs@mbari.org (R.E. Sherlock)
}

restricted the flow of pack ice, thus reducing the area of open water and resulting in a $>40 \%$ decrease in primary production of the region (Arrigo et al., 2002). A reduction of this magnitude impacts all trophic levels including top predators. Large icebergs may have large-scale effects but they are rare compared to the much greater abundance of smaller icebergs. Smaller icebergs have a much larger surface area to volume ratio, provide relatively more substrate for organisms and when considered in total, could impact a vast region of the Southern Ocean. There are an estimated 200,000 icebergs in the Southern Ocean with linear dimensions of tens of meters to tens of kilometers (Orheim, 1988).

Icebergs may have important structuring effects on local pelagic communities (Smith et al., 2007). Increased concentrations of Fe and chlorophyll $a$ accompanied by increased abundance of nanoplankton were measured in the wake of a drifting iceberg in the Southern Indian Ocean (de Baar et al., 1995; Raiswell et al., 2008; Schwarz and Schodlok, 2009). At higher trophic levels, the diversity of acoustically-reflective targets, believed to be zooplankton and micronekton, were twice as high under a free-drifting iceberg when compared to surrounding open water in the Weddell Sea (Kaufmann et al., 1995). Fish have been observed in small caves within the walls of a coastal iceberg off Greenland (Holmquist, 1958) and grounded icebergs in the Ross Sea (Line, 2000; Stone, 2003). In addition, fish have been observed attached to the smooth surface of a grounded tabular iceberg in the Davis Sea (Gruzov et al., 1967) and to the subsurface of a marginal ice shelf in the SE 
Weddell Sea (Gutt, 2002). Top predators such as Chinstrap penguins and Antarctic fur seals are known to associate with icebergs in the NW Weddell Sea (Joiris, 1991; Rubic et al., 1991). Communities of seabirds, including Southern Fulmars, Wilson's Storm Petrels, Antarctic Petrels and Mottled Petrels have been associated with icebergs in the Ross Sea (Ainley et al., 1984) as well as in the NW Weddell Sea (Smith et al., 2007; Ruhl et al., this issue). Recruitment of these predators may be an active response to shelter or enhanced productivity, or it may be the result of passive entrapment and entrainment of prey.

Little is known about the organisms associated with icebergs. In this study we used a small, remotely operated vehicle (ROV) to survey, sample and characterize the macro-organisms living in close proximity to and on the submerged faces of free-drifting, tabular icebergs in the Weddell Sea in the late austral spring of 2005 (December) and late summer (March/April) of 2009. At the same time, we recorded salinity, temperature and chlorophyll data to determine how those parameters varied with distance from the iceberg and how that variability affected the associated organisms.

\section{Materials and methods}

ROV dives for this study were made in December of 2005 and March/April of 2009 from the ARSV L.M. Gould and RVIB N.B. Palmer, respectively (Smith, this issue). The ROV was equipped differently during each of those years. The 2005 expedition was primarily a reconnaissance mission made on a limited budget and the ROV (Deep Ocean Engineering Phantom HD2) initially had no hydrographic or biological sampling capability, only a video camera and incandescent lights. The ROV was subsequently outfitted with a modified $0.25-\mathrm{m}^{2}$ plankton net during the cruise and with it we sampled tufts of attached diatoms, as well as a rock lying on the shallow shelf of a tabular iceberg. Although the ROV was rated to a depth of $600 \mathrm{~m}$, it was limited to depths that could be reached with its 300-m tether (Hobson et al., this issue). Over the course of 7 dives made in the NW Weddell Sea in the late Austral spring, we obtained video footage of fish and diatoms on the ice, and krill, salps and other gelatinous zooplankton nearby (Smith et al., 2007; Table 1).

Based upon what we learned during our 2005 cruise, the ROV was upgraded to provide more power and was outfitted to collect High Definition (HD) video imagery, biological samples and hydrographic data in 2009. A Sony HJDR-HC5 camcorder transmitted live video to the surface where it was recorded on mini-DV tape. HD video images were captured and stored to the camera's flash memory. The ROV was equipped with a 29-chamber suction sampler carousel and a fluorinert-filled, pressure-compensated Rule 24 VDC suction pump. The suction sampler carousel served as a repository for individual samples drawn into the carousel through either a $0.14-\mathrm{m}^{2}$ plankton net $(202 \mu \mathrm{m})$ mounted on the forward portion of the ROV toolsled, or a suction nozzle mounted in front of the ROV on the bumper bar. The plankton net was used for collecting zooplankton during transecting operations. The suction nozzle was used to collect attached diatoms and macroplankton from the ice face and water column. The plankton net and suction nozzle could not both be used on the same dive. An individual suction sampler chamber consisted of a $5.1 \mathrm{~cm}$ diameter by $7.6 \mathrm{~cm}$ long, open-ended acrylic tube fitted with $202-\mu \mathrm{m}$ mesh nylon sock to retain the sample as water was drawn through by the suction pump.

Conductivity, temperature and depth data were collected with a Falmouth Scientific Micro-CTD MCTD III, while chlorophyll $a$ and turbidity were measured with a WETLabs ECO FLNTU fluorometer and turbidity sensor attached to the CTD. Because these instruments were mounted near the bottom of the ROV, measurements made while descending were more likely to represent the undisturbed water column; however, in some cases only ascending data were obtained (Table 1). For calibration, the ROV CTD/fluorometer was removed and mounted alongside the CTD/fluorometer used aboard the RVIB Nathaniel B. Palmer's CTD rosette. Measurements of chlorophyll $a$ made with the ROV were thus cross-calibrated over a cast to $600 \mathrm{~m}$ and corrected via bottle samples analyzed in the shipboard lab. Speed through water and distance traveled was determined with a General Oceanics Model $2031 \mathrm{H}$ electronic flowmeter with a low-speed impeller. Distance and orientation to the iceberg face were determined and recorded for later analysis with a Kongsberg-Simrad Mesotech 1000 scanning sonar. See Hobson et al. (this issue) for more detail on the ROV's specifications and capabilities.

In 2009 the better-equipped ROV made 7 complete biology dives on 3 icebergs that ranged in size from $<0.5$ to $32 \mathrm{~km}$ in greatest dimension. All the icebergs we examined in 2009 occurred over the Powell Basin of the Weddell Sea (Fig. 1). During a typical dive the ship usually moved $1-2 \mathrm{~km}$ (Table 1 ) due to linear or rotational movement of the iceberg.

Most dives were made on the lee side of an iceberg. Choosing a dive site depended on several factors, among them were iceberg surface topography and the apparent likelihood of calving as well as the current relative to the iceberg and other icebergs in the vicinity. The ROV was deployed with the ship's starboard A-frame. Once in the water, the vehicle transited to the iceberg on the surface and then dove upon reaching the ice face. Occasionally, conditions like brash ice in the water required that we make the last part of the approach to the ice face submerged. A floating tether configuration was used for these missions due to the long stand-off distance required between the ship and iceberg. This allowed the tether to be continuously visible to the ship's bridge crew and tether handlers as it streamed out 100 to $300 \mathrm{~m}$ to the iceberg. However, this left it vulnerable to being snagged by passing growlers or brash ice.

The position of the ROV relative to the movement of the iceberg was calculated from the ship's track, heading, and the fact that the ROV was always deployed off the starboard side. Shipboard GPS was used to calculate the distance and direction traveled (Table 1). ROV speed varied greatly based on prevailing conditions. Current effects on the tether were by far the largest factor in determining speed. Whether the ROV dove up or downstream of an iceberg varied and, in some cases, changed during a dive.

Two types of ROV missions were performed for this study: ice face surveys and vertical transects. The primary purpose of the surveys was to explore the ice face from close to the surface waterline down to the apparent bottom of the iceberg. Detailed observations of the ice structure and associated biota were made on these dives, and targeted specimens were collected for identification in the lab using the $0.25-\mathrm{m}^{2}$ plankton net as a scraper/collector in 2005, or with the suction sampler in 2009. In addition to the dedicated survey dives, a single descending ice-face survey was also conducted on each of the transecting dives prior to initiating those activities. The relative abundance of diatom tufts was estimated during ice face surveys and scored on a scale of 0 (no diatoms visible) to 5 ( $>6$ tufts/ablation cup). In total, ice-face surveys were completed on 5 dives in 2005 and 7 dives in 2009. Vertical transecting missions were run to quantify and compare organisms living on and very close to the iceberg with those living up to $45 \mathrm{~m}$ away. No dives were repeated in the same place on any iceberg.

Whenever possible, vertical transects were made at 3 distances from the iceberg: $0-5,10-15$ and $30-45 \mathrm{~m}$ (Table 1 ). The operational goal for these transects was to move diagonally up or down the face of the iceberg and/or water column at about a $45^{\circ}$ angle to maintain movement forward into undisturbed water, as well as to maintain 


\begin{tabular}{|c|c|c|c|c|c|c|c|c|c|c|c|c|}
\hline 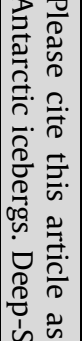 & $\begin{array}{l}\text { Table } 1 \\
\text { ROV dives }\end{array}$ & hade in the Weddell Se & during the & ate fall of 2009 ar & late summer of 2 & 05. ea $=$ Eusirus anta & tica; $\mathrm{f}=$ fish; ts=diatom tu & s (Thalassior & s signyensis). & & & \\
\hline 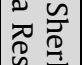 & Dive \# & $\begin{array}{l}\text { Date (mm/dd/yyyy) } \\
\text { duration (hh:mm) }\end{array}$ & Iceberg & $\begin{array}{l}\text { Depth iceberg } \\
\text { bottom }(\mathbf{m})\end{array}$ & $\begin{array}{l}\sim \text { Dist. fr. } \\
\text { ice }(\mathbf{m})\end{array}$ & Location & Mission & Epifauna & $\begin{array}{l}\text { Dive } \\
\text { direction }\end{array}$ & $\begin{array}{l}\text { Ship's heading } \\
\text { (deg.) }\end{array}$ & $\begin{array}{l}\sim \text { Dist. Travelled } \\
(\mathbf{k m})\end{array}$ & $\begin{array}{l}\text { Iceberg edge } \\
\text { sampled }\end{array}$ \\
\hline 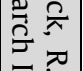 & 4 & $\begin{array}{l}03 / 17 / 2009 \\
02: 18\end{array}$ & $C-18 a$ & 190 & $1 \mathrm{~m}$ & NW Powell Basin & survey/collect epifauna & $\mathrm{ts}, \mathrm{f}$ & $\mathrm{N}$ & $270-310$ & 1.3 & side/trailing \\
\hline 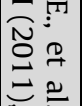 & 6 & $\begin{array}{l}03 / 20 / 2009 \\
02: 59\end{array}$ & $C-18 a$ & 148 & $\begin{array}{l}1 \mathrm{~m} \\
15 \mathrm{~m} \\
40 \mathrm{~m}\end{array}$ & NW Powell Basin & survey/transects & $\mathrm{f}$ & $\mathrm{NE}$ & $279-290$ & 1.4 & trailing \\
\hline$\frac{0}{2} \cdot z$ & 8 & $\begin{array}{l}\text { 03/23/2009 } \\
03: 06\end{array}$ & C-18a & 195 & $\begin{array}{l}1 \mathrm{~m} \\
\text { (x } 2 \text { de-scents) }\end{array}$ & NW Powell Basin & survey/collect epifauna & $\mathrm{f}$ & $\mathrm{N}$ & $334-357$ & 0.7 & leading \\
\hline $\mid \begin{array}{ll}4 & 0 \\
\dot{\hat{n}} & 0 \\
& 0 \\
0 & 0\end{array}$ & 13 & $\begin{array}{l}\text { 04/02/2009 } \\
03: 01\end{array}$ & $C-18 a$ & 176 & $1 \mathrm{~m}$ & N Powell Basin & survey & $\mathrm{ts}, \mathrm{f}$ & S & $340-10$ & 1.9 & side/ leading \\
\hline 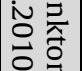 & 17 & $\begin{array}{l}04 / 06 / 2009 \\
02: 00\end{array}$ & IA-4 & 167 & $\begin{array}{l}1 \mathrm{~m} \\
30 \mathrm{~m}\end{array}$ & S Powell Basin & survey/transects & $\mathrm{ts}, \mathrm{f}$ & NW & $290-313$ & 1.1 & leading \\
\hline 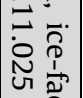 & 18 & $\begin{array}{l}04 / 10 / 2009 \\
03: 24\end{array}$ & IA-5 & 190 & $\begin{array}{l}1 \mathrm{~m} \\
15 \mathrm{~m} \\
40 \mathrm{~m}\end{array}$ & W Powell Basin & survey/transects & ea,f & NE & $30-70$ & 1.6 & leading \\
\hline $\begin{array}{l}0 \\
\overline{0} \\
0\end{array}$ & 2 & $\begin{array}{l}\text { 12/11/2005 } \\
03: 13\end{array}$ & W-86 & 208 & & survey & $\mathrm{ts,f}$ & & & & & \\
\hline $\begin{array}{l}\overrightarrow{2} \\
\cong\end{array}$ & 3 & $\begin{array}{l}12 / 15 / 2005 \\
02: 46\end{array}$ & W-86 & 210 & & survey & $\mathrm{ts,f}$ & & & & & \\
\hline 뭉 & 4 & $\begin{array}{l}\text { 12/18/2005 } \\
03: 06\end{array}$ & A-52 & & & survey & & & & & & \\
\hline 肴. & 5 & $\begin{array}{l}12 / 19 / 2005 \\
02: 23\end{array}$ & A-52 & & & survey & ts,f & & & & & \\
\hline$\underset{\vdots}{\Xi}$ & 6 & $\begin{array}{l}12 / 20 / 2005 \\
01: 31\end{array}$ & A-52 & & & Survey & & & & & & \\
\hline
\end{tabular}




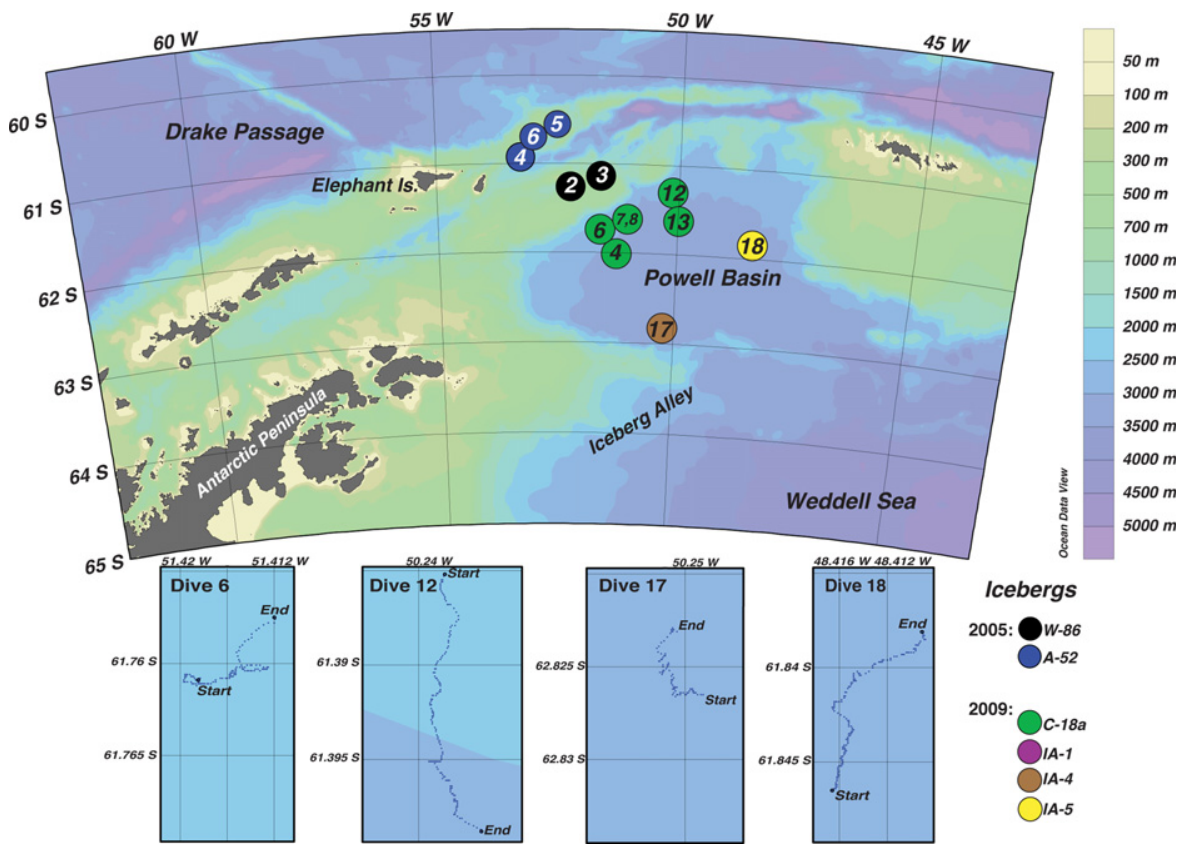

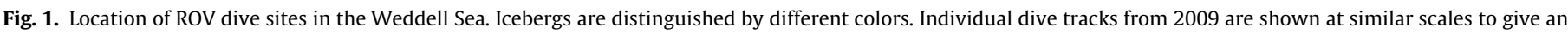
indication of iceberg movement during the 2-4 hour long dives. IA=Iceberg Alley. All icebergs were tabular except for IA-1.

flow through the plankton net as we changed depth. While transecting, plankton samples from discrete depth intervals were collected in individual suction sampler chambers. The volume of water filtered on each segment of a transect was estimated by calculating vector distance traveled (using horizontal distance travelled and vertical change in depth) and multiplying by the open area of the plankton net mouth. Three complete transect series of 3 transects each $(\sim 1 \mathrm{~m}, 15 \mathrm{~m}$, and $40 \mathrm{~m})$ were made in total. Two of those occurred at iceberg C-18a and the third at iceberg IA-5, in the western Powell Basin. A fourth transect series made at IA- 4 omitted the middle distance because of time constraints (Table 1 ).

The method for ice face transects was standardized in order to achieve consistent sampling. The vehicle was oriented at about a $30^{\circ}$ angle from parallel with the plane of the ice face and then it proceeded forward, and either upward or downward, as described above for the water-column transects. This angle gave us the best lighting and contrast to recognize animals close to the ice or to the ROV. Using the angle of approach to the ice face and the viewing angle of the HD lens, an average viewed surface area of $1.6 \mathrm{~m}^{2}$ was calculated. Organisms seen and sampling events were annotated with the MBARI video annotation and reference system - VARS (Bush and Robison, 2007). Video was further annotated in greater detail in the lab, in order to describe iceberg structure and associated organisms. Video quantification of zooplankton was precluded by changing lighting conditions close to the ice and by image dropouts when the ROV bumped the ice and the camera stopped writing to its hard drive.

Aboard the RVIB Nathaniel B. Palmer, each plankton sample was photographed then divided with a plankton splitter. One half of each sample was frozen $\left(-80^{\circ} \mathrm{C}\right)$ for subsequent analysis (biomass and/or $\mathrm{CHN}$ ) and the other half was roughly sorted into taxonomic groups. Once ashore after the cruise, taxa were more carefully sorted. Copepods, while very abundant, were not identified to species and thus were excluded from abundance analyses. However, copepods were retained as a component of calculated biomass. Frozen samples were dried at $30{ }^{\circ} \mathrm{C}$ for 48 hours on pre-weighed filters and overall biomass was estimated from each half sample by doubling its weight.

Multi-dimensional scaling (MDS) was used to examine links between community composition, the iceberg sampled, and sampling distance from the ice. Because of sampling constraints imposed by operating near icebergs, we transformed abundance data to presence/absence to account for speed-induced sampling bias. Presence/absence weights equally those taxa less frequently sampled. The presence/absence of invertebrate fecal pellets, fish fecal pellets, and fish scales were included in the list of taxa because the ROV moved too slowly to effectively sample animals like fish and adult euphausiids, but the presence of their fecal pellets was considered to be a proxy. The null hypotheses of no differences in community composition with: (1) distance from the iceberg sampled, and (2) overall distance sampled (spanning the Powell Basin); were tested using analysis of similarity (ANOSIM) and the RELATE function in the multivariate statistical software, Primer (Clarke and Gorley, 2006). A data matrix composed of the taxa sampled by the ROV was constructed. In order to test the first hypothesis, a model distance matrix was made that grouped samples collected during each dive by their respective distance from the ice. The model matrix for overall distance sampled was constructed based on the metric latitude and longitude for each dive.

\section{Results}

In 2005, five ROV dives were completed on two separate icebergs that ranged in size from 2 to $21 \mathrm{~km}$ in greatest dimension. These dives were exploratory in nature and consisted of ice face surveys and the collection of attached diatoms. These surveys yielded information on the subsurface ice face structure, and the vertical distribution of cryopelagic fish and attached diatoms, as well as, krill, salps and other near-ice zooplankton (Smith et al., 2007). Samples of attached diatoms were collected for identification (Robison et al., this issue). No quantitative data were collected on these dives.

\subsection{Iceberg structure}

The icebergs we studied varied in size, but typically they shared some above-water features like vertical walls and an undercut 
(A)

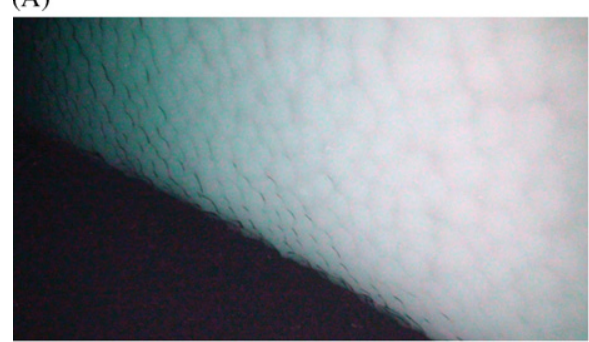

(C)

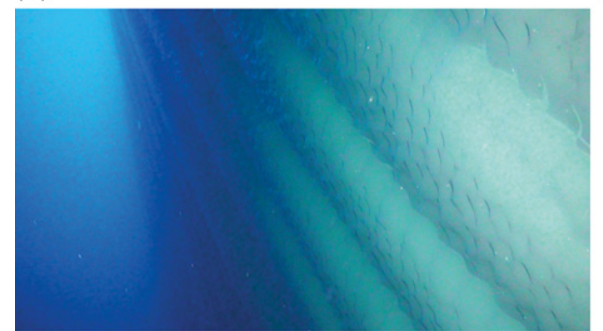

(B)

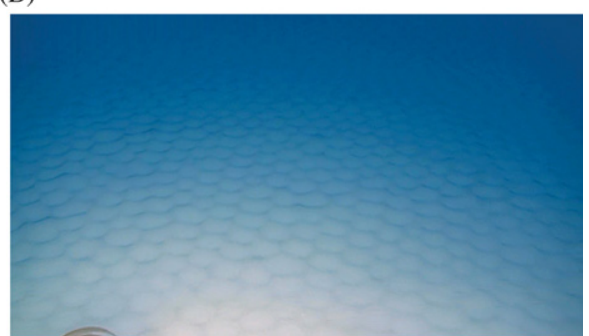

(D)

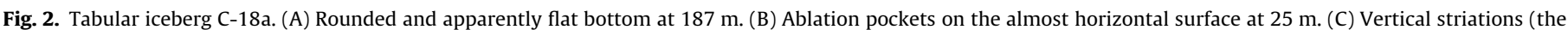

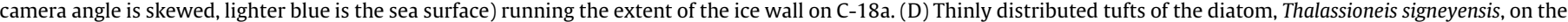
wall of C-18a, $27 \mathrm{~m}$.

carved by the sea surface. Underwater, tabular icebergs typically had 3 distinct features: shelf, side and bottom. The shelf began just below the sea surface and sloped gradually deeper. Side-scan sonar images of one tabular iceberg measured a shelf width of $c a 55 \mathrm{~m}$ (S. Rock, pers com). However, shelf width varied greatly on and between icebergs. The shelf break, which occurred between $20-40 \mathrm{~m}$, was blunt and rounded. There the ice face sloped vertically $90^{\circ}$ or more. Below the break, the face of the iceberg usually sloped slightly inward, generally 5 to $10^{\circ}$, and varied with depth. This nearly vertical wall extended to the bottom of the iceberg, which was also rounded and led to a seemingly flat bottom (Fig. 2A) that occurred between 120-200 $\mathrm{m}$ for the icebergs we examined in 2009 (Table 1 ). Though the size of their shelves varied considerably, these features were consistent for icebergs A-52, W-86, C-18a and a smaller tabular iceberg, IA-4. The tabular iceberg IA-5 - similar in size to IA-4 - was ca $1.5 \mathrm{~km}$ long and $190 \mathrm{~m}$ deep and did not exhibit a shelf where we dove. The lack of a shelf on this iceberg could be an indication that IA-5 had recently calved off another iceberg.

We did not intentionally dive under any iceberg to observe bottom topography. However, on dive \#4 we were pulled under iceberg C-18a by a current strong enough that the vehicle could not make way under its own power and we had to haul in tether to pull it clear. Fortunately, the bottom was flat and without ice projections. Forward-looking sonar found no projections off the bottom of any iceberg to at least $50 \mathrm{~m}$ under the iceberg. The apparently flat bottom on iceberg IA-5 (dive 18) extended to a radius of at least $300 \mathrm{~m}$.

Ablation pockets formed the most consistent visual, subsurface feature on icebergs. The majority of the subsurface ice we observed bore cupped, golf ball-like depressions (ablation pockets) that varied in diameter from $\mathrm{ca} 10$ to $20 \mathrm{~cm}$ and were usually a few centimeters deep. The size and spacing of the pockets was generally consistent within a given region. With the outer edges of the pockets overlapping those of their nearest neighbors, a hexagonal pattern was produced by the ice ridges that formed the rims around the pockets (Fig. 2A-D). At different depths and at different stages of ice dissolution, the clarity of the hexagonal shape varied, but upon close inspection, the general shape could be discerned. Ablation pockets were present irrespective of ice orientation and were observed on vertical as well as horizontal surfaces; however, they appeared to be much less regular the few times we ventured under an iceberg.
Vertical striations were sometimes seen on ice walls of tabular bergs. In some cases they were tens of centimeters deep and appeared to run the extent of the wall, from bottom to shelf (Fig. 2C). More rarely, we encountered deep crevasses or caves that broke the vertical surface of large icebergs. Twice in 2005 we encountered small holes where gas bubbles seeped from the ice. Huppert and Josberger (1980) postulated that bubbles emanating from the ice could have caused the vertical striations they saw in laboratory experiments; however, no striations were associated with these bubble streams. No bubbles were associated with the larger vertical striations we observed in 2009. In one instance, the cleft continued over the shelf shoulder and ran along the horizontal ice shelf, indicating that bubbles could not be the sole cause of such features.

In the late austral spring of 2005 we also observed streams of fresh water cascading off the large tabular iceberg, A-52. Nothing similar was seen in the late summer (March/April) of 2009. All large, tabular icebergs we studied calved while we observed them irrespective of the season, occasionally at inconvenient times.

\subsection{Ice-face diatoms}

Tufts of the diatom, Thalassioneis signyensis, (Robison et al., this issue) were found growing on 4 tabular icebergs: A-52 and W-86 (2005), C-18a and IA-4 (2009). Distribution was patchy, although when present, they always occurred on the rims of ablation pockets (Fig. 2D). Ice-face diatom distribution and abundance was notably different between our December (late spring) 2005 and March/ April (late summer) 2009 studies. The diatoms were seen on 3 of 5 dives in 2005 and tuft density was highest on the shelf, at a depth of $25 \mathrm{~m}$ (Fig. 3). The maximum depth of occurrence was $95 \mathrm{~m}$, but density generally decreased quickly below $50 \mathrm{~m}$. During the 2009 expedition, diatom tufts were seen on 3 of 7 dives. On the openocean iceberg, C-18a, diatom tufts were only seen below the shelf break, with the highest density between 38 and $55 \mathrm{~m}$ depth, but they occurred in patches as deep as $100 \mathrm{~m}$. East of the Antarctic Peninsula, the small, tabular iceberg IA-4, had its highest density of diatom tufts between 20 and $25 \mathrm{~m}$ depth, with a number of less dense patches found as deep as 125 to $145 \mathrm{~m}$. 

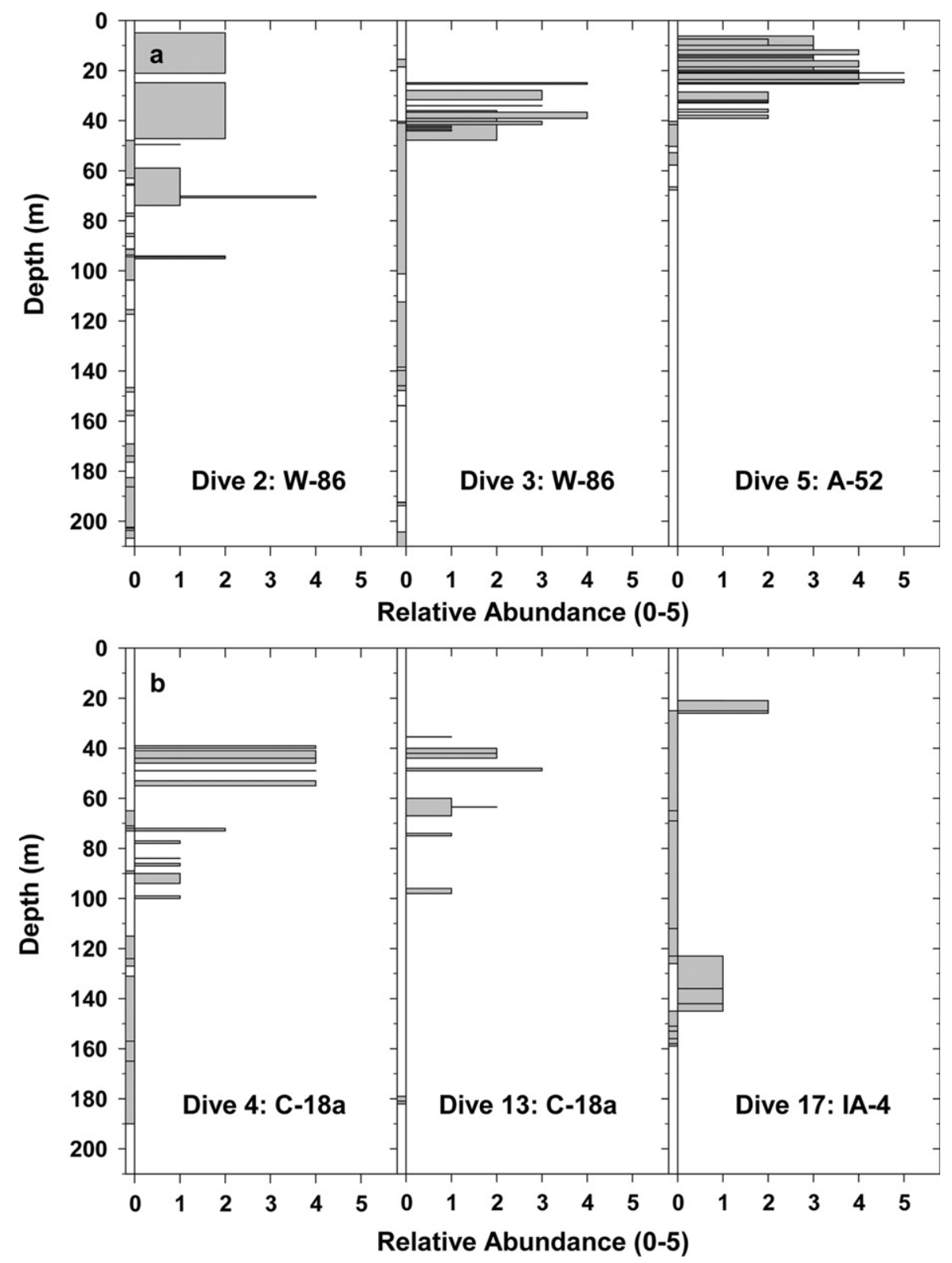

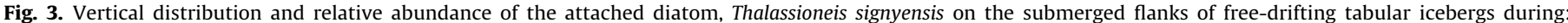

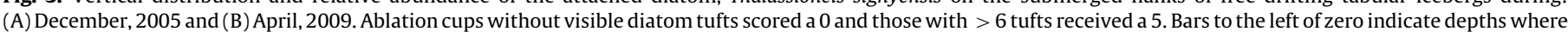
surveys were conducted, but no diatoms seen.

\subsection{Ice-face epifauna}

ROV observations were limited to organisms approaching $0.5 \mathrm{~cm}$ in size and up. In this size-range, relatively few ice-face epifauna were observed. Fish were the most notable exceptions. Although not seen on every dive, cryopelagic fish were found on all tabular icebergs in 2005 and 2009. Unfortunately, we were only able to obtain video footage of the fish despite numerous attempts to catch them with the plankton net and suction sampler. The video images alone were inadequate to provide positive identification.

All but two of the fish appeared to be juvenile nototheniids ranging in size from 34 to $45 \mathrm{~mm}$ and similar in physical morphology. There were two general color morphs with some intermediate variations that may be artifacts of video angles and illumination. The most abundant type had no skin pigment but had silvery reflective tissue lining the abdominal cavity and some exterior surfaces on the eye (Fig. 4A). The second type differed most notably from the first by having dark pigment in the form of vertical bars on the caudal portion of the body and patches on the surface of the abdomen. (Fig. 4B).

Based upon published descriptions (Eastman and DeVries, 1985; Eastman, 1993) and similarities with the juvenile cryopelagic fish observed by Gutt (2002), it is likely that the unpigmented fish is Pagothenia borchgrevinki. Of the other three known cryopelagic fish species, only Trematomus nicolai has a barred pigmentation pattern similar to the fish we observed. Both of these species have been reported to live on icebergs: $P$. borchgrevinki was observed living in holes (Line, 2000) and T. Nicolai was observed at $30 \mathrm{~m}$ depth "attached to" the smooth surface of an iceberg by Gruzov et al. (1967; see Andriashev, 1970).

The behavior and distribution of fish types we observed were similar. They were generally found adhering to the nearly vertical ice, facing up or down, along one of the rising slopes of the ablation pockets (Fig. 4C). Due to their reflective abdominal pigmentation, they were often difficult to discern against the substrate, demonstrating that they are well adapted to blend in with this habitat. 
Their escape response was minimal and usually consisted of a kick and glide to an adjacent pocket.

With one exception, all 464 fish observed in this study occurred below the shelf break at depths between 42 and $206 \mathrm{~m}$. Their lower limit was generally defined by the bottom of the iceberg. One pigmented fish was seen on top of the ledge at approximately $25 \mathrm{~m}$ depth in a dense diatom field in 2005. All 3 ice-face video transects carried out in 2009 showed a bi-modal distribution with the upper
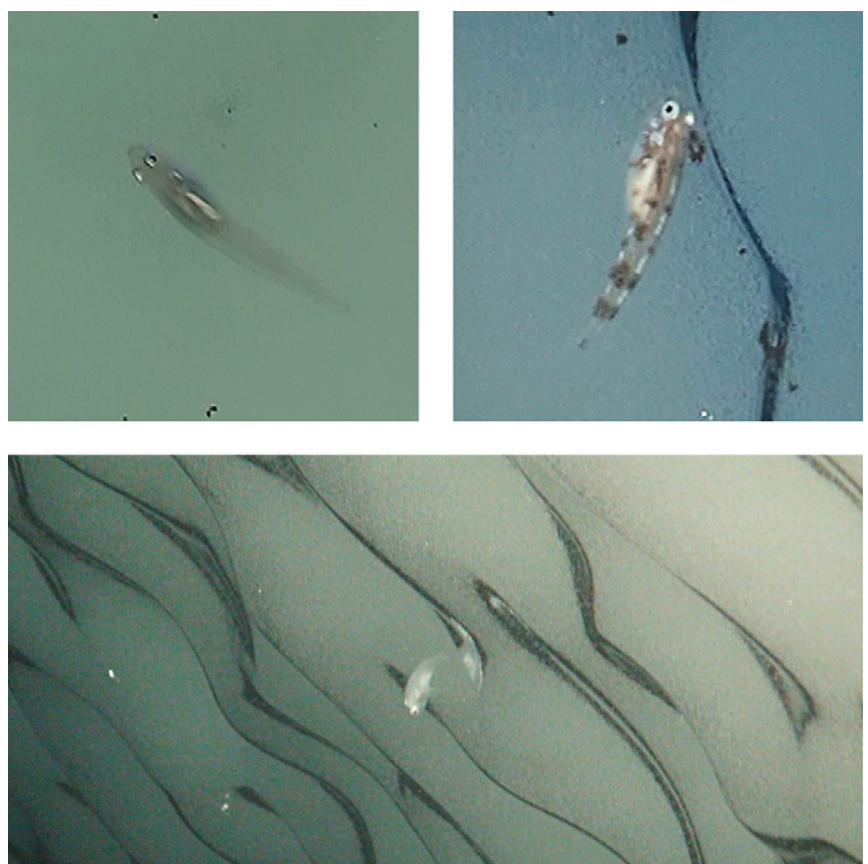

Fig. 4. Cryopelagic nototheniid fish found on the submerged sides and bottoms of free-drifting tabular icebergs: (A) unpigmented (B) pigmented and (C) typical resting position. node between 40 and $95 \mathrm{~m}$ and the lower node covering the lower $40 \mathrm{~m}$ of the ice face. (Fig. 5). The highest density of fish seen during a transect segment was $3.2 \mathrm{fish} / \mathrm{m}^{2}$ between $164-171 \mathrm{~m}$ depth with eight fish seen in a single $1.6 \mathrm{~m}^{2}$ video frame taken a few meters above the transition to the flat bottom of the iceberg. Cryopelagic fish were observed resting under the iceberg, as well as on the nearly vertical faces of the icebergs.

\subsection{Transecting - biological data and observations}

Vertical transects were challenging because of the short, $600 \mathrm{~m}$ tether, iceberg movement, calving, currents, and potential tethertangling ice at the sea surface. Consequently, ROV transecting dives varied in time from 2.5-4 hours. During that time the iceberg typically travelled $1-1.5 \mathrm{~km}$ (Table 1 ).

Zooplankton observed in the water surrounding the icebergs were similar to samples collected nearby in the $10 \mathrm{~m}^{2}$ MOCNESS trawls (Kaufmann et al., this issue). The most easily recognized macrozooplankton seen on video included Salpa thompsoni, the medusae Periphylla periphylla and Calycopsis borchgrevinki, the

(A)

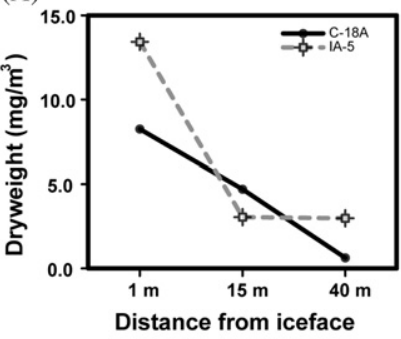

(B)

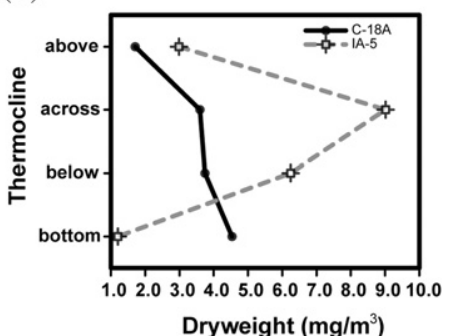

Fig. 6. Comparison of total biomass for ROV plankton samples collected (A) 1,15 and $40 \mathrm{~m}$ from the ice face and (B) above, below and across the thermocline of two tabular icebergs, C-18a and IA-5. 'Bottom' distinguishes the samples collected at the bottom of the iceberg, adjacent to the ice face.

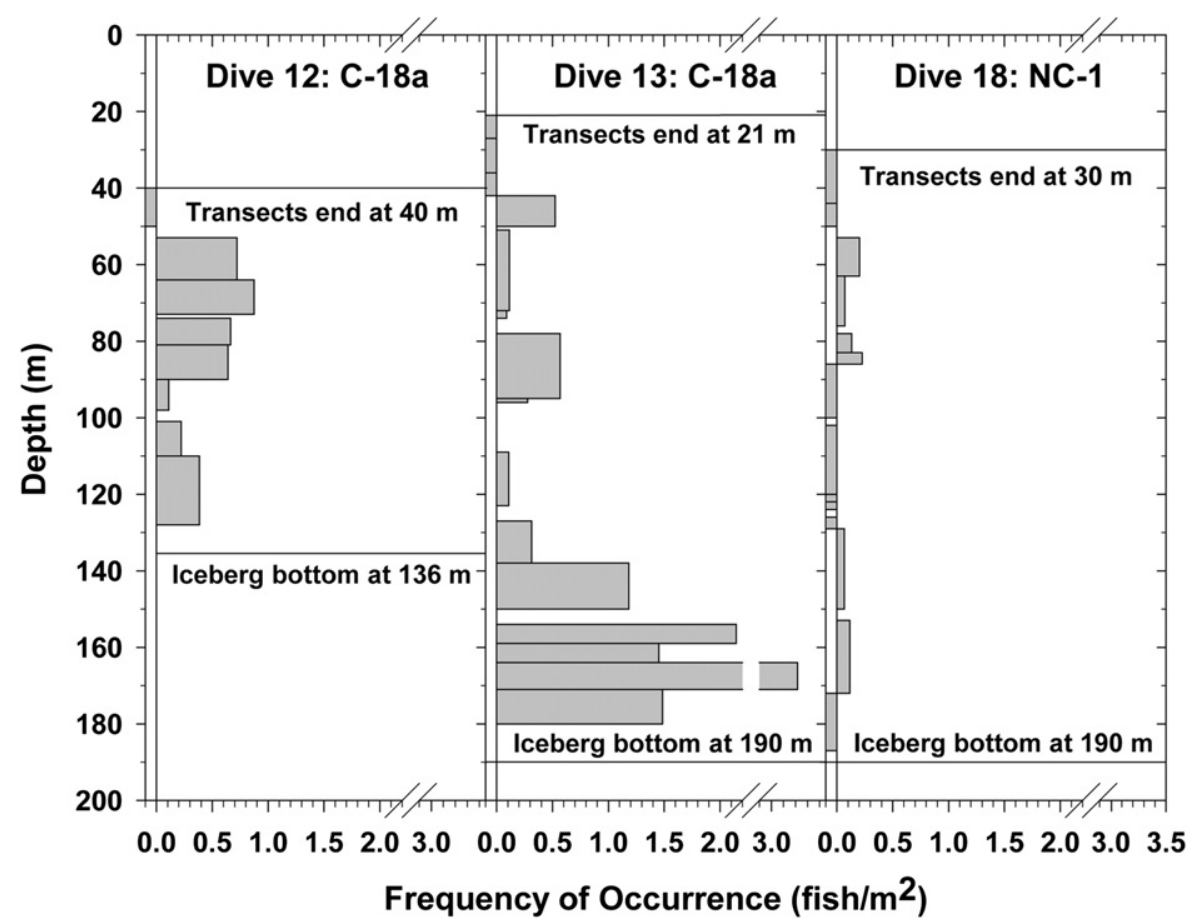

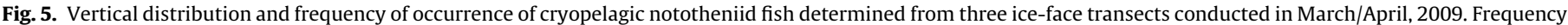
of occurrence bars to the left of zero indicated depths where transects were conducted, but no fish seen. 
ctenophores Callianira antarctica and Beroe spp., as well as the calycophoran siphonophore, Diphyes antarctica. Small pteropods, probably Spongiobranchia australis, were seen less often. Schools of krill, Euphausia superba and Thysanoessa macrura, were seen on most dives but their occurrence was patchy. Even on dives when few krill were seen, their fecal pellets were often present in high numbers. Krill seemed more abundant in the December of 2005 than in March/April of 2009 and peak density occurred in a large, deep cave, which the ROV was pulled into by a strong current.

The amphipod Eusirus antarctica was another commonly seen crustacean. On the smaller tabular berg, IA-5, we observed large numbers of them clinging to the ice wall from $c a 45-75 \mathrm{~m}$. They
(A)

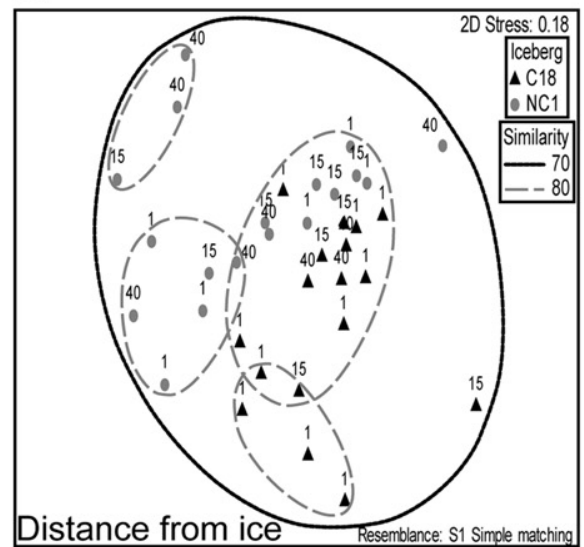

(B)

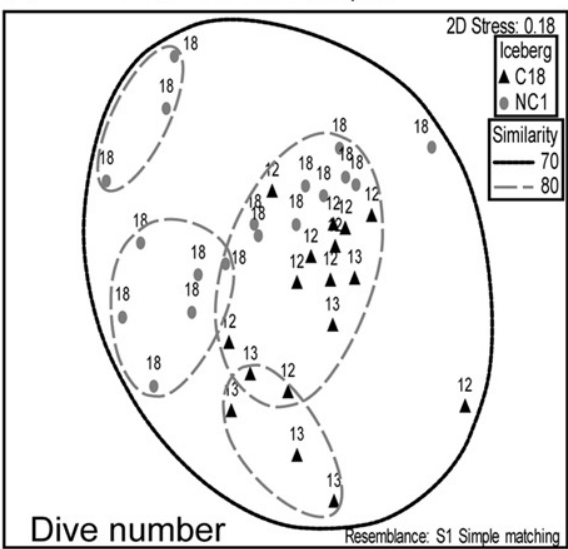

(C)

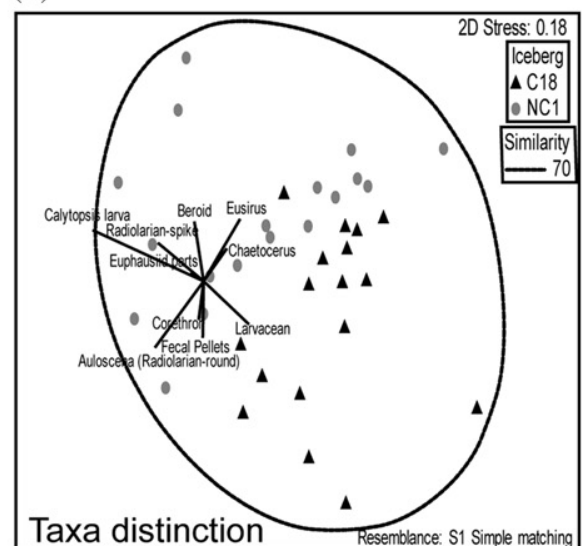

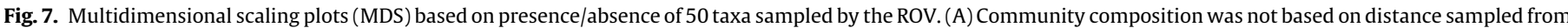

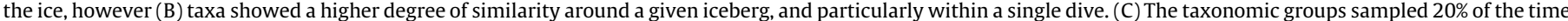
or more are shown. The direction of the vector approximates sample location and the length corresponds to abundance.

(A) Salinity (psu) $\quad$ Temp ${ }^{\circ} \mathrm{C} \quad \mathrm{Chl}$ a (ug/l)

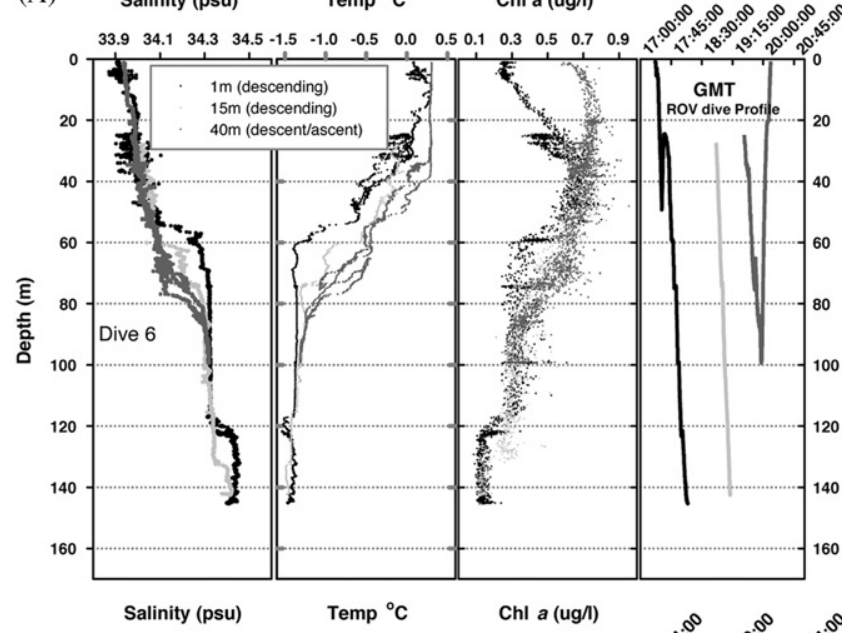

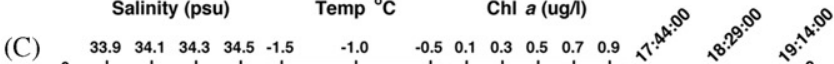

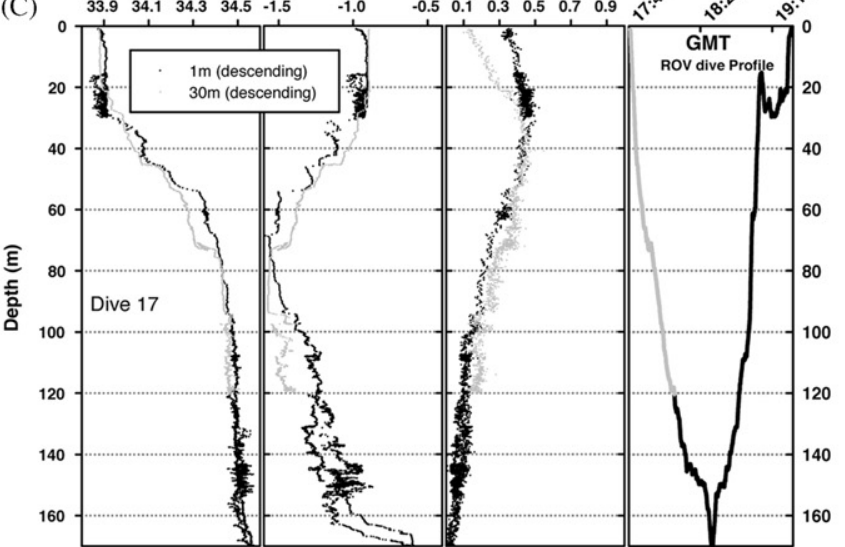

(B)

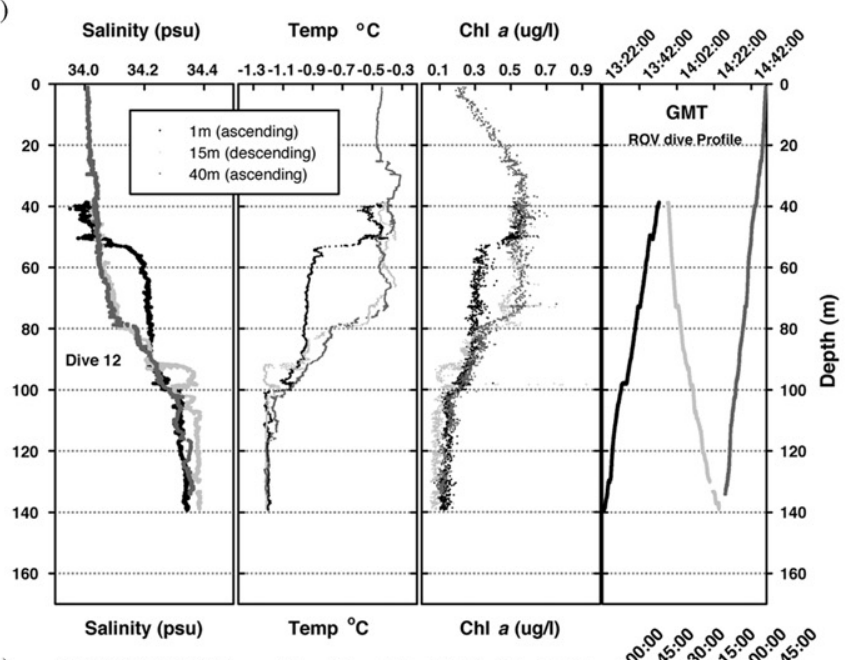

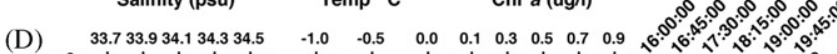

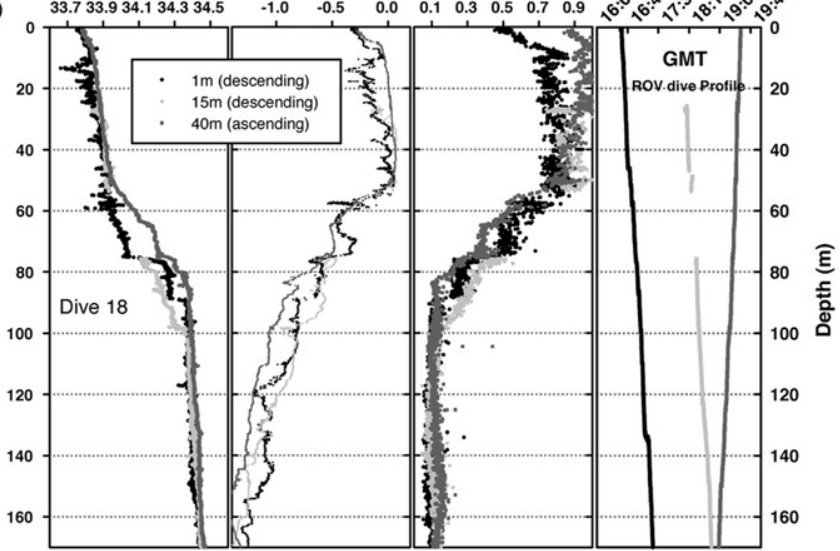

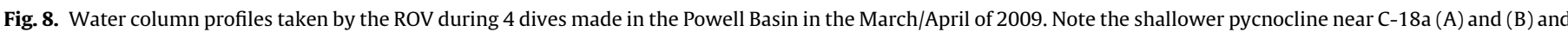

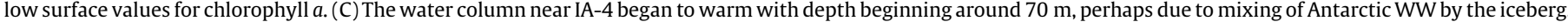
(D) Temperature and salinity near the smaller IA-5 differed from C-18a, although chlorophyll was slightly reduced nearer the iceberg. 
were easily disturbed and readily swam off the ice when startled by the lights, noise, or vibrations of the ROV. Previously we had seen E. antarctica on the ice but only in small numbers. They were readily identified on video, but were also captured by the suction sampler and the plankton net as we transected close to the iceberg.

Notably absent from the ice as well as the water column nearby were other amphipods, tomopterid and alciopid worms, animals commonly encountered in nearby $10 \mathrm{~m}^{2}$ MOCNESS trawls (Kaufmann et al., this issue).

Because of the small net opening and $202 \mu \mathrm{m}$ mesh size, plankton collected by the plankton net during transects tended to be small. In approximate order of most to least abundant these included: diatoms (Corethron sp.), calanoid copepods, small chaetognaths (Pseudosagitta $s p$ ), dinoflagellates (Chaetocerus sp.), radiolarians, tintinnids, phyllodocid polychaetes, cladocerans and appendicularians. In all, 50 taxa collected by the plankton net were identified for community analyses.

While transecting vertically, the ROV sampled between 18.6 and $52.3 \mathrm{~m}^{3}$ of seawater during each profile (at distances $c a 1,15$ and $40 \mathrm{~m}$ from the ice). Samples were taken above, below, and across the thermocline and sampling depth varied with the dive and the distance from the iceberg. No proximity-related change was apparent in plankton community composition within $40 \mathrm{~m}$ of an iceberg, but biomass increased within $5 \mathrm{~m}$ of the ice face. Samples collected near the ice face of icebergs C-18a and IA-5 averaged
$10.8 \mathrm{mg} / \mathrm{m}^{3}$ dry weight (range: $8.2-13.4 \mathrm{mg} / \mathrm{m}^{3}$ ), compared with $2.5 \mathrm{mg} / \mathrm{m}^{3}$ dry weight (range: $0.6-4.7 \mathrm{mg} / \mathrm{m}^{3}$ ) for samples taken at 15 and $40 \mathrm{~m}$ away from the ice face (Fig. 6A). The spatial patterns of biomass and composition are similar to those reported by Kaufmann et al. (this issue) albeit at a larger scale; they found macrozooplankton and micronekton biomass was highest at trawling sites closest to the icebergs, while no change in community composition was apparent out to a distance of $18.5 \mathrm{~km}$. Samples taken across and below the thermocline generally had higher biomass ( $\mathrm{mg} / \mathrm{m}^{3}$ dry weight) than samples from above it. The exception was the sample taken near the bottom of iceberg IA-5, which yielded the lowest biomass we collected (Fig. 6B).

We saw a high degree of similarity in the taxa sampled with the plankton net. An MDS plot showed little distinction between the sampled invertebrates based on distance from the ice face (Fig. 7A). Instead, the plot indicated a greater degree of similarity in community composition around a given iceberg and within a given dive than within any distance grouping from the ice (Fig. 7B). Ultimately ANOSIM confirmed that no significant differences existed in community composition based on distance from the ice $(p=0.50)$. The null hypothesis of no change in community composition with distance sampled across the Powell Basin was tested and rejected $(\mathrm{p}=0.019, \mathrm{Rho}=0.114)$, indicating that taxa did change with distance sampled over the Powell Basin.

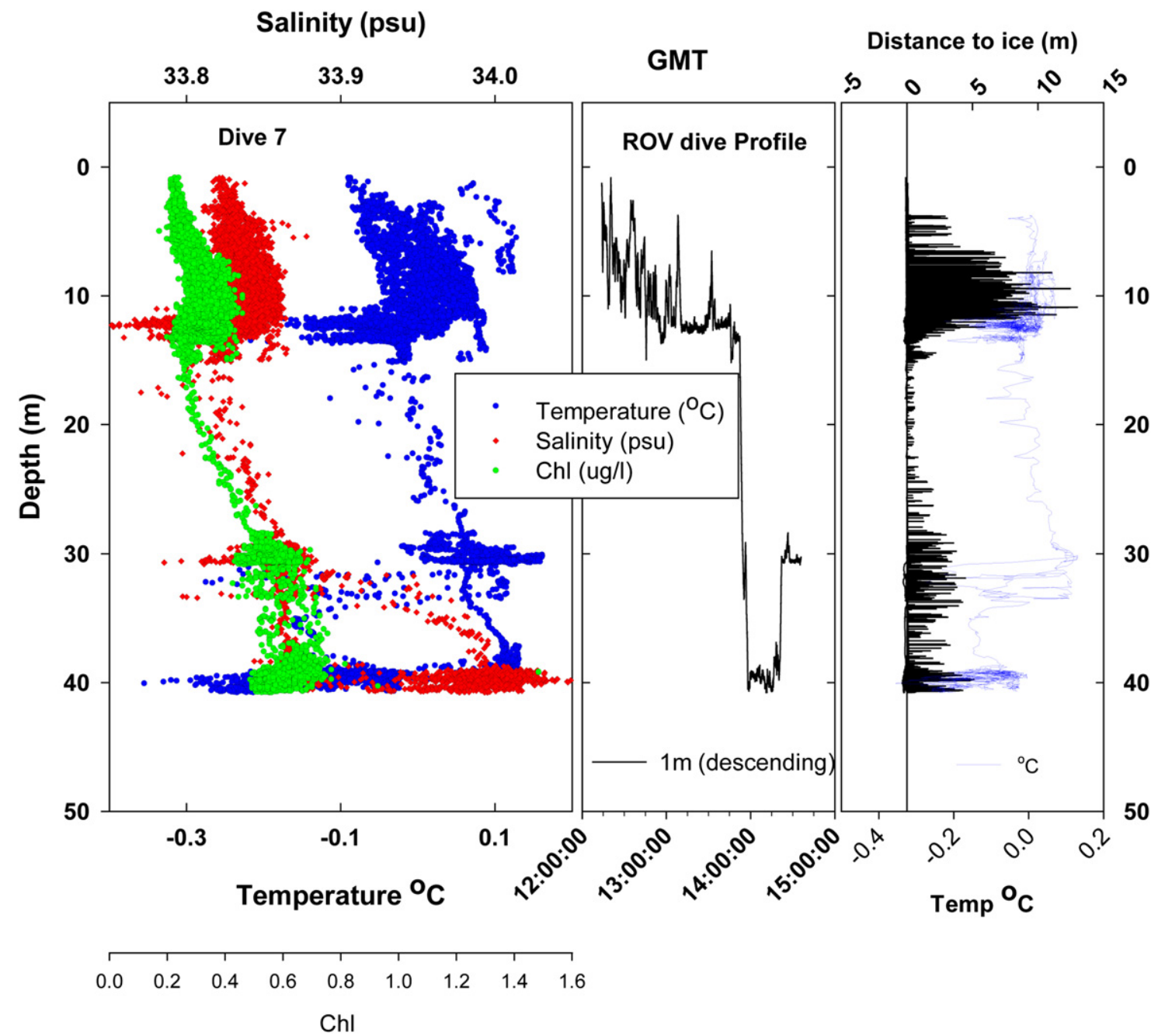

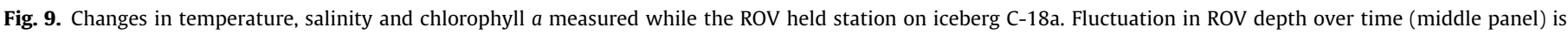

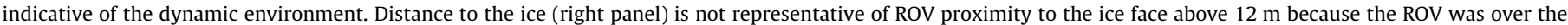
horizontal shelf. Changes in temperature as the ROV descended (right panel) may indicate horizontal flow of seawater away from the iceberg. 


\subsection{Transecting - hydrographic data and observations}

The ROV typically dove to depths between $150-200 \mathrm{~m}$ in order to reach the bottom of an iceberg. Over the Powell Basin this depth range encompassed two water masses: Antarctic Surface Water (AASW) and Winter Water (WW) (Smith et al., 1999; Stephenson et al., this issue). At $1 \mathrm{~m}$ from $\mathrm{C}-18 \mathrm{a}$ the pycnocline was conspicuous and fairly flat. At $40 \mathrm{~m}$ from the ice face, the thermocline was typically less sharply defined and occurred deeper (Fig. 8A,B). However, there were exceptions to these generalities; temperature and salinity varied, sometimes appreciably, over distances of tens of meters from an iceberg.

Hydrographic data taken while the ROV made way on the surface, from the ship to an iceberg, showed relatively fresh water of 33.634.0 psu that usually and somewhat surprisingly became more saline as the ROV dove close to the iceberg (Fig. 8A-C). Temperature decreased as the ROV approached the iceberg $\mathrm{Ca}-0.3$ to $-1.0^{\circ} \mathrm{C}$, and usually continued to decrease with depth (Fig. 8A,B,D). The hydrography of IA-4 stood out in that temperature began to increase at about $100 \mathrm{~m}$ (Fig. 8C). Although not usually observed, this phenomenon was also seen at iceberg C-18a for dive \#8, with warming beginning at about $150 \mathrm{~m}$. Chlorophyll $a$ was typically low in the surface water and lower near the iceberg than farther away (Fig. 8A, B, D). The water column near IA-4 (dive \#17) was an exception and chlorophyll was slightly higher farther away from the ice face (Fig. 8C). Lower chlorophyll, temperature and salinity values near the surface are likely the result of dilution by meltwater.

Measured near the ice, temperature, salinity and chlorophyll $a$ varied even while station-keeping at the same depth. Watersampling ROV dives (not part of this study) were typically spent pumping water from several depth stations adjacent to the ice. This dive plan allowed the ROV to sample water from a particular depth over time and demonstrated the variability in temperature and salinity close to the ice while depth remained relatively constant (Fig. 9). The clearest indication of meltwater, concentrated near the surface, came from these dives as well.

\section{Discussion}

Complex interactions between physical and biological processes are important in structuring marine ecosystems (Daly and Smith, 1993). ROVs provide a unique opportunity to make integrated biological, chemical and physical measurements adjacent to icebergs. However, small ROVs lack the motive power to overcome the constraints of currents, ship movement, and tether management. The precision with which station-keeping, profiling, and sampling can be accomplished are all limited by power in this dynamic environment. Nevertheless we were able to make, for the first time, measurements in close proximity to free drifting icebergs; measurements not afforded by more traditional oceanographic methods.

\subsection{Hydrography}

Icebergs cool, freshen, and disturb the water through which they pass. A number of laboratory investigations have attempted to replicate how icebergs influence the environment in which they melt (Gade, 1979; Huppert and Turner, 1980; Neshyba and Josberger, 1980; Huppert and Josberger, 1980; Jacobs et al., 1981; Josberger and Martin, 1981). These studies revealed a millimeters-thin, upward flowing boundary flanked by a thicker, more turbulent, downward flowing layer that was warmer and saltier than the boundary (nearice) layer and colder than the far-field water. As this outer layer of water flowed down, it entrained meltwater from the inner boundary layer. Depth, salinity and thereby density, increased until reaching neutral buoyancy at which point the water flowed away from the ice in nearly horizontal layers (Huppert and Josberger, 1980). Such horizontal flows may have been the cause of the stepped decreases seen in some temperature profiles, e.g., dive 7 on C-18a (Fig. 9).

An interesting incongruity in our CTD data was the apparent lack of meltwater as the ROV dove on an iceberg. Stephenson et al., (this issue) measured relatively low density water in hydrocasts made outside our sampling range, at C-18a. We expected the water to be less saline close to the iceberg and were surprised when the CTD usually showed just the opposite (Fig. 8). Because the CTD could never be closer to the ice than $c a 0.5 \mathrm{~m}$, it is possible that the instrument was just too far away from the ice and that it remained outside the extent of the innermost, upward-flowing boundary layer described by Huppert and Josberger (1980) and Huppert and Turner (1980).

At times an upward flowing layer adjacent to the ice was apparent in the HD video. Gelatinous zooplankton were good current indicators and Salpa thompsoni were particularly conspicuous as they moved vertically, telltales in the current (online supporting video). At times there were currents emanating from under the iceberg strong enough to prevent the ROV from making a descent (e.g., Dive 6). Conversely, there were also currents that carried the ROV under the ice (e.g., Dive 4). The ROV dove most often on the leading edge of icebergs. This was unintentional and likely a consequence of diving in the lee of the wind. Only dives 4 and 6 (C-18a) occurred on the trailing edge, yet the current flow under the iceberg was quite different between those two dives. Shear forces like these are thought to be due to the interactions of wind and current, the shape and extent of the iceberg's sides, its translocations and movement through the water. They are distinct from the turbulent flow of meltwater described by Huppert and Turner (1980) and Huppert and Josberger (1980).

Zooplankton may be concentrated by biological as well as physical factors. Doty and Oguri (1956) found increased productivity upstream of islands surrounded by otherwise nutrient-poor oceanic water. Alldredge and Hamner (1980) discovered that shear zones formed by tidal currents around islands served to concentrate zooplankton up to 40 times that of water outside such zones. Like islands, icebergs often have complex topography and may be quite large. Unlike islands, icebergs are usually free of the seafloor and are moved by winds and currents. If those forces are complementary, the iceberg will move faster than the current. If wind and currents oppose each other, the entire flow regime around the iceberg changes.

Thus, icebergs undoubtedly share the "bewildering array of variables" Hamner and Hauri (1981) observed around islands and reefs; variables that are compounded by an iceberg's movement through the water. The complex currents, gyres and eddys that formed around a reef can be of great importance to the local distribution of fishes and plankton (Hamner and Hauri, 1981) and it is reasonable to expect that the same holds true for icebergs. However, the dynamic nature of the wake and water flow surrounding icebergs was particularly apparent at the scales sampled by the ROV as currents changed, often over the course of a single dive. Factors such as whether the ROV dove on the leading or trailing edge of the iceberg (Table 1) likely had little bearing on whether it was actually in the wake of the iceberg or not. Turbulent flows near the ice face may have been more consistently important in aggregating zooplankton.

\subsection{Biological oceanography}

Microbial and microalgal communities proliferate on and in sea ice as well as in nearby waters that are modified by the presence of that ice (Brierley and Thomas, 2002). Micrometazoans like flagellates and ciliates also inhabit the ice where they are grazed on by zooplankton (Garrison, 1991). The colonization of sea ice and the growth of sea-ice biota depend on the state of the ice as well as the physical processes 
that form and deteriorate it. Its microstructure helps define how ice biota colonize pack ice (Ackley and Sullivan, 1994). The glacial ice of large, tabular bergs is very different from pack ice; however, the surface of icebergs is subject to constant change due to currents, calving, melting, and erosion. Krill and amphipods that temporarily inhabit icebergs likely do so because there are algae and micrometazoans present for forage. Like the diatom tufts, which grow at the periphery of ablation pockets, their patchiness may be due to the changing quality of the ice surface itself.

Tufts and mats of diatoms, fish, and amphipods, were the most common organisms found on the submerged ice of icebergs. Where they occurred, diatoms were densest above the associated pycnocline, although diatom tufts were confirmed down to depths of about $100 \mathrm{~m}$. The shallower node of the nototheniid distribution overlapped with the distribution of the diatoms but was independent of diatom presence. Fish living on the icebergs were typically more common below the pycnocline. However, O'Grady and DeVries (1982) demonstrated that $P$. borchgrevinki and T. nicolai can effectively osmoregulate over a range of 500 to $1750 \mathrm{~m}$, which would indicate that both species should tolerate greater salinity gradients than we saw along the entire ice face. Stone (2003) observed an undetermined species of cryopelagic fish living in freshwater pools at the edge of icebergs, further evidence of their adaptability in this dynamic environment.

As none of these fish were seen away from the ice face, or collected in trawls conducted nearby our dive sites (Kaufmann et al., this issue), we assume that icebergs are a preferred habitat for this stage of their life cycle. Given that their vertical distribution begins at about $40 \mathrm{~m}$ and that none were seen in ice caves or burrows, it may be that the upper range of their depth distribution is limited by predation from shallow-diving birds. Free-drifting icebergs provide mobile habitats with ablation pockets as hiding and resting surfaces, access to a rich zooplankton food source, and the potential for long-range dispersal within the polar front.

The community composition of the plankton we collected was about 70\% similar between the two tabular icebergs, C-18a and IA-5 (Fig. 7C). Larvaceans were not collected at IA-5 but were relatively common, if exceedingly small, at C-18a. Euphausiid calytopsis larvae were found at both icebergs, but only once on C-18a. For iceberg IA-5, the samples with the highest biomass were largely due to collections of calytopsis larvae and the relatively large amphipod, Eusirus antarctica, in the near-ice samples.

Biomass varied with depth and with distance from an iceberg. This could result from physical factors at the leading edge of the iceberg, where we usually sampled, or be a response by grazers to the ice-attached algal communities. The range of these values from far to near the ice face $\left(\sim 3-11 \mathrm{mg} / \mathrm{m}^{3}\right.$, Fig. $\left.6 \mathrm{~A}\right)$ is similar to data from plankton trawls made in the same area at similar depths and time of year (Boysen-Ennen et al., 1991). For iceberg C-18a as well as for IA-5, the near-ice samples had more organisms than did samples collected from further away (Fig. 6A). With one exception, the highest planktonic biomass collected occurred across or below the pycnocline (Fig. 6B). However, the depth of the pycnocline was shallower nearer an iceberg and the Antarctic Winter Water mass extended vertically, even in comparison with water ca $40 \mathrm{~m}$ away (Fig. 8, and Stephenson et al., this issue). Thus while the pycnocline was a prominent physical feature and a potential biological gradient, it was not the only one. This depth range also generally includes the chlorophyll maximum (Vernet et al., this issue) and it is likely an interaction of factors that led to more organisms being collected across and below the thermocline.

We found no evidence that invertebrate communities were entrained or entrapped by icebergs. In fact, the macroplankton we collected varied only slightly over the entire cruise in 2009. The taxa from a given dive were fairly similar in spite of being sampled at three different distances from the ice (Fig. 7A,B), indicating that geography and different water types or, possibly time, better explained the changes in the invertebrate communities we observed. The organisms found on or adjacent to the ice face are either highly mobile (e.g., euphausiids, amphipods, and fish), or are specially adapted (e.g., fish and diatoms) to live in that dynamic environment. Plankton like Corethron sp., Chaetocerus sp., radiolarians and copepods may be able to quickly benefit in the wake of a large iceberg; however, macrozooplankton present nearby seem to be the consequence of being concentrated in the turbulent flows adjacent to an iceberg and/or stirred up to the shallower pycnocline.

\section{Summary and conclusions}

- Small ROVs can be useful tools to study icebergs but low motive power and small payloads limit their efficacy.

- The five tabular icebergs we examined shared these structural features: a horizontal shelf, nearly vertical sides, extensive ablation pockets and an apparently flat bottom.

- Plankton biomass was higher within $5 \mathrm{~m}$ of the icebergs we sampled than it was between 15 and 40 m distant.

- The community composition adjacent to icebergs varied over the geographical scale of the Powell Basin, but did not vary with distance out to $40 \mathrm{~m}$ from any iceberg we examined.

- Diatom communities associated with ablation pockets were found at shallower depths and higher densities in the late spring than in late summer.

- Cryopelagic nototheniid fish were common and conspicuous on the submerged flanks of the icebergs we examined.

\section{Acknowledgments}

This research was funded by a National Science Foundation grant (ANT-0636813) to K. Smith and B. Robison and by the David and Lucile Packard Foundation. We thank L. Bird, B. Hobson, P. McGill, and A. Sherman for herculean efforts to modify and maintain the ROV. Craig Dawe skillfully piloted the ROV to an equal number of launches and recoveries. Shipboard support and tether management was provided by the aforementioned as well as K. Smith, J. Ellena, C. Hexel, A. Kahn, D. Nail-Meyer and the very capable Raytheon Polar Services support group. Without the coordination of Captain M. Watson and all crew on the RVIB N.B. Palmer, as well as Captain R. Verret and the crew on the ARSV L.M Gould, the ROV work would not have been possible. K. Walz identified and sorted many plankton and assisted with figures. B. Schlining helped with hydrography. This ms benefitted from the critique of 3 reviewers and we thank them. $\mathrm{R}$. Wilson taught something to everyone, not the least of which was how to sharpen a knife on a coffee cup.

\section{References}

Ackley, S.F., Sullivan, C.W., 1994. Physical controls on the development and characteristics of Antarctic sea ice biological communities-a review and synthesis. Deep-Sea Research I 41, 1583-1604.

Ainley, D.G., O'Connor, E.F., Boekelheide, R.J., 1984. The marine ecology of birds in the Ross Sea. Antarctica. Ornithological Monographs 32, 1-97.

Andriashev, A.P., 1970. Cryopelagic fishes of the Arctic and Antarctic and their significance in polar ecosystems. Antarctic Ecology 1, 297-304.

Alldredge, A.L., Hamner, W.M., 1980. Recurring aggregation of zooplankton by a tidal current. Estuarine and Coastal Marine Science 10, 31-37.

Arrigo, K.R., van Dijken, G.L., Ainley, D.G., Fahnestock, M., Markus, T., 2002. Ecological impact of a large Antarctic iceberg. Geophysical Research Letters 29, 8-1.

de Baar, H.J.W., de Jong, J.T.M., Bakker, D.C.E., Loscher, B.M., Veth, C., Bathmann, U., Smetacek, V., 1995. Importance of iron for plankton blooms and carbon dioxide drawdown in the Southern Ocean. Nature (373), 412-415.

Bindschadler, R., 2006. Climate change. Hitting the ice sheets where it hurts. Science $311,1720-1721$.

Bindschadler, R., Rignot, E., 2001. Crack! in the polar night. EOS, Transactions American Geophysical Union, 82. 
Boysen-Ennen, E., Hagen, W., Hubold, G., Piatkowski, U., 1991. Zooplankton biomass in the ice-covered Weddell Sea, Antarctica. Marine Biology 111, 227-235.

Brierley, A.S., Thomas, D.N., 2002. Ecology of southern ocean pack ice. Advances in Marine Biology 43, 171-276

Bush, S.L., Robison, B.H., 2007. Ink utilization by mesopelagic squid. Marine Biology $152,485-494$.

Clarke, K.R., Gorley, R.N., 2006. PRIMER User Manual/Tutorial, Version 6. PRIMER-E Ltd., Plymouth, United Kingdom 190.

Daly, K.L., Smith Jr, W.O., 1993. Physical-biological interactions influencing marine plankton production. Annual Review of Ecology and Systematics 24, 555-585.

Doty, M.S., Oguri, M., 1956. The island mass effect. Journal du Conseil Permenent International pour l'Exporation de la Mer 22, 33-37.

Eastman, J.T., DeVries, A.L., 1985. Adaptations for cryopelagic life in the Antarctic Notothenioid Fish Pagothenia borchgrevinki. Polar Biology 4, 45-52.

Eastman, J.T., 1993. Antarctic fish biology: evolution in a unique environment. Academic Press, San Diego. US.

Gade, H.G., 1979. Melting of ice in sea water: a primitive model with application to the Antarctic ice shelf and icebergs. Journal of Physical Oceanography 9, 189-198.

Garrison, D.L., 1991. Antarctic sea ice biota. Integrative and Comparative Biology $31,17$.

Gruzov, E.N., Propp, M.V., Pushkin, A.F., 1967. Biological associations of coastal areas of the Davis Sea (based on the observations of divers). Soviet Antarctic Expedition Information Bulletin 6, 523-533.

Gutt, J., 2002. The Antarctic ice shelf: an extreme habitat for notothenioid fish. Polar Biology 25, 320-322.

Hamner, W.M., Hauri, I.R., 1981. Effects of island mass: Water flow and plankton pattern around a reef in the Great Barrier Reef lagoon, Australia. Limnology and Oceanography 26 (6), 1084-1102.

Hobson, B.W., Sherman, A.D., McGill, P.R. Imaging and sampling beneath freedrifting icebergs with a remote operated vehicle (ROV). Deep-Sea Research II, this issue [doi:10.1016/j.dsr2.2010.11.006].

Holmquist, C., 1958. An observation on young specimens of Ammodytes dubius. Meddelser om Gronland 159, 4-14.

Huppert, H.E., Josberger, E.G., 1980. The melting of ice in cold stratified water. Journal of Physical Oceanography 10, 953-960.

Huppert, H.E., Turner, J.S., 1980. Ice blocks melting into a salinity gradient. Journal of Fluid Mechanics, 100

Jacobs, S., 2006. Observations of change in the Southern Ocean. Philosophical Transactions of the Royal Society A: Mathematical, Physical and Engineering Sciences 364, 1657.

Jacobs, S.S., Huppert, H.E., Holdsworth, G., Drewry, D.J., 1981. Thermohaline steps induced by melting of the Erebus Glacier Tongue. Journal of Geophysical Research 86, 6547-6555.

Joiris, C.R., 1991. Spring distribution and ecological role of seabirds and marine mammals in the Weddell Sea, Antarctica. Polar Biology 11, 415-424.

Josberger, E.G., Martin, S., 1981. Convection generated by vertical icewalls. Journal of Fluid Mechanics 111, 439-473.

Kaufmann, R.S., Robison, B.H., Reisenbichler, K.R., Sherlock, R.S., Osborn, K. Composition and structure of macrozooplankton and micronekton communities in the vicinity of free-drifting Antarctic icebergs. Deep-Sea Research II, this issue [doi:10.1016/j.dsr2.2010.11.026].

Kaufmann, R.S., Smith, K.L., Baldwin, R.J., Glatts, R.C., Robison, B.H., Reisenbichler, K.R. 1995. Effects of seasonal pack ice on the distribution of Macrozooplankton and Micronekton in the Northwestern Weddell Sea. Marine Biology 124, 387-397.
Lazzara, M.A., Jezek, K.C., Scambos, T.A., MacAyeal, D.R., Veen, C.J.V.D., 1999 On the recent calving of icebergs from the Ross Ice Shelf. Polar Geography 23, 201-201.

Line, L., 2000. Frozen Fish Diving beneath an iceberg, Norbert Wu found these hardy creatures. AUDUBON-NEW YORK 102, 120-120.

Long, D.G., Ballantyne, J., Bertoia, C., 2002. Is the number of Antarctic icebergs really increasing? EOS Transactions 83, 469.

Neshyba, S., Josberger, E.G., 1980. On the estimation of Antarctic iceberg melt rate. Journal of Physical Oceanography, 10.

O'Grady, S.M., DeVries, A.L., 1982. Osmotic and ionic regulation in polar fishes. Journal of Experimental Marine Biology and Ecology 57, 219-228.

Ohshima, K.I., Kawamura, T., Takizawa, T., Ushio, S., 1994. Step-like structure in temperature and salinity profiles, observed near icebergs trapped by fast ice Antarctica. Journal of Oceanography 50, 365-372.

Orheim, O., 1988. Antarctic icebergs-production, distribution and disintegration. Annals of Glaciology 11, 205.

Pisarevskaya, L.G., Popov, I.K. 1990. Free-drifting icebergs and thermohaline structure. In: Proceedings of the International Symposium at St. Petersburg: IAHS Publ. no. 208: 447-454.

Raiswell, R., Benning, L.G., Tranter, M., Tulaczyk, S., 2008. Bioavailable iron in the Southern Ocean: the significance of the iceberg conveyor belt. Geochemical Transactions 9, 7.

Robison, B.H., Vernet, M. Smith, K.L Algal communities attached to free-drifting Antarctic icebergs. Deep-Sea Research II, this issue [doi:10.1016/j.dsr2.2010.11.024]

Rubic, C.A., Ainley, D.G., Fraser, W.R., 1991. Habitat selection by marine mammals in the marginal ice zone. Antarctic Science 3, 181-186.

Ruhl, H.A., Ellena, J.A., Wilson, R.C., Helly, J. Seabird aggregation around free-drifting icebergs in the northwest Weddell and Scotia Seas. Deep-Sea Research II, this issue [doi:10.1016/j.dsr2.2010.11.028].

Scambos, T.A., Hulbe, C., Fahnestock, M., Bohlander, J., 2000. The link between climate warming and break-up of ice shelves in the Antarctic Peninsula. Journal of Glaciology 46, 516-530.

Schwarz, J.N., Schodlok, M.P., 2009. Impact of drifting icebergs on surface phytoplankton biomass in the Southern Ocean: Ocean colour remote sensing and in situ iceberg tracking. Deep-Sea Research I 56, 1727-1741.

Smith, D.A., Hofmann, E.E., Klinck, J.M., Lascara, C.M., 1999. Hydrography and circulation of the West Antarctic Peninsula Continental Shelf. Deep-Sea Research I 46, 925-949.

Smith, Jr., K.L. Free-drifting icebergs in the Southern Ocean: an overview. Deep-Sea Research II, this issue [doi:10.1016/j.dsr2.2010.11.003].

Smith Jr, K.L., Robison, B.H., Helly, J.J., Kaufmann, R.S., Ruhl, H.A., Shaw, T.J., Twining B.S., Vernet, M., 2007. Free-drifting icebergs hot spots of chemical and biological enrichment in the Weddell Sea. Science 317, 478-482.

Stephenson, G.R., Sprintall, J., Gille, S.T., Vernet, M., Helly, J., Kaufmann, R. Subsurface melting of a free-floating Antarctic iceberg. Deep-Sea Research II, this issue [doi:10.1016/j.dsr2.2010.11.009].

Stone, G.A., 2003. Ice island: expedition to Antarctica's largest iceberg. New England Aquarium, Boston MA.

Vernet, M., Sines, K., Chakos, D., Cefarelli, A., Ekern, L., Impacts on phytoplankton dynamics by free-drifting icebergs in the NW Weddell Sea. Deep-Sea Research II, this issue [doi:10.1016/j.dsr2.2010.11.022].

Wadhams, P., 1986. The seasonal ice zone. In: Untersteiner, N. (Ed.), The Geophysics of Sea Ice. Plenum, New York, pp. 825-991. 